\title{
Natural scene statistics relate to perceptual salience of second-, third-, and fourth-order spatial correlations
}

\author{
Ann M Hermundstad ${ }^{1 *+}$, John Briguglio ${ }^{1+}$, Mary M Conte ${ }^{2}$, Jonathan D Victor ${ }^{2}$, Gasper Tkacik ${ }^{3 \dagger}$, \\ Vijay Balasubramanian ${ }^{1 \dagger}$
}

From Twenty Second Annual Computational Neuroscience Meeting: CNS*2013

Paris, France. 13-18 July 2013

The statistical regularities of natural scenes are a starting point for understanding the characteristics of early visual processing, e.g. the center-surround architecture of retinal ganglion cell receptive fields. Can this matching between natural signal statistics and neural processing mechanisms be extended beyond the sensory periphery? Our recent work [1] revealed that human sensitivity to fourth-order correlations in synthetic textures, known to arise in cortex, is closely related to the structure of fourth-order spatial correlations in natural scenes. This leads us to propose a specific organizing principle: The perceptual salience of visual textures increases with the variance, or unpredictability, of the corresponding correlations over the ensemble of natural scenes. To test this principle, we examined the statistical regularities of binarized natural images as characterized by correlations between adjacent pixels within a $2 \times 2$ square. Local binary textures can be described by four types of secondorder correlations between pixels arranged in vertical $\left(\beta_{\mathrm{V}}\right)$, horizontal $\left(\beta_{\mathrm{H}}\right)$ and diagonal $\left(\beta_{\backslash}\right.$ and $\left.\beta_{/}\right)$configurations, four types of third-order correlations between pixel triplets $\left(\theta_{1,2,3,4}\right)$, and one type of fourth-order correlation

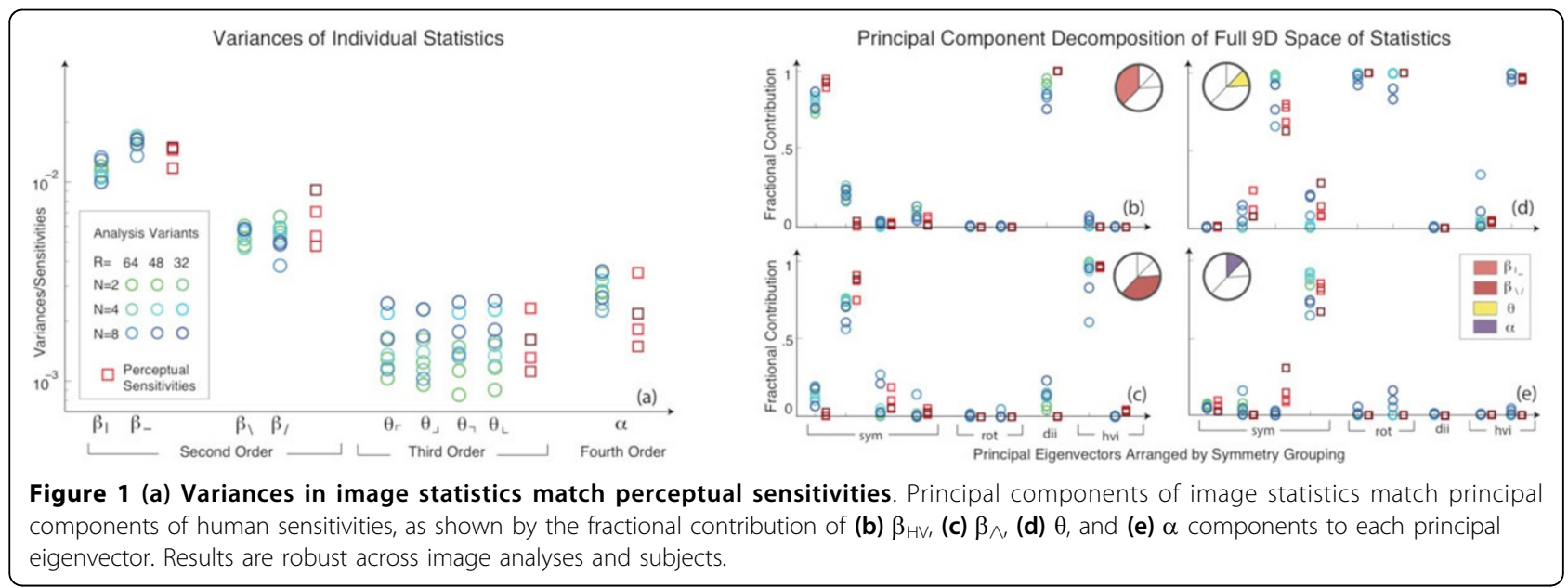

\footnotetext{
* Correspondence: annherm@physics.upenn.edu

† Contributed equally

'Department of Physics and Astronomy, University of Pennsylvania,

Philadelphia, PA 19104, USA

Full list of author information is available at the end of the article
}

\section{Ciomed Central}

○ 2013 Hermundstad et al; licensee BioMed Central Ltd. This is an Open Access article distributed under the terms of the Creative Commons Attribution License (http://creativecommons.org/licenses/by/2.0), which permits unrestricted use, distribution, and reproduction in any medium, provided the original work is properly cited. 
between pixel quadruplets $(\alpha)$. We measured the values of these correlations in a large ensemble of image patches, and we compared the results to psychophysical experiments that measure human sensitivity to synthetic visual textures. Both the ordering and magnitude of natural image variances was found to match perceptual sensitivities to synthetic textures generated with the corresponding correlations (Figure 1a). Furthermore, the principal components of the full 9D space of image statistics match the principal components of the corresponding space of sensitivities (Figure 1b-e). These results suggest that central neural mechanisms are efficiently tuned to the higher-order statistics of natural scenes.

\section{Methods}

Natural Image Analysis: 88 grayscale images were block averaged in $\mathrm{N} \times \mathrm{N}$ patches to remove camera pixel matrix artifacts and divided into $\mathrm{R} \times \mathrm{R}$ patches. Image patches were whitened and binarized at their pixel intensity median. Psychophysical Analysis: Subjects were asked to identify a target (4-alternative forced choice) in brief (120-160 ms) presentations of $64 \times 64$-check binary images subtending $15 \times 15 \mathrm{deg}$. The target/background distinction was defined by a specific set of local image statistics, whose strengths were varied parametrically across trials [2].

\section{Author details}

'Department of Physics and Astronomy, University of Pennsylvania,

Philadelphia, PA 19104, USA. ${ }^{2}$ Weill Cornell Medical College, New York, NY 10065, USA. ${ }^{3}$ Institute of Science and Technology Austria, Klosterneuburg, Austria.

Published: 8 July 2013

\section{References}

1. Tkacik G, Prentice JS, Victor JD, Balasubramanian V: Local statistics in natural scenes predict the saliency of synthetic textures. Proc Natl Acad Sci USA 2010, 107(42):18149-18154.

2. Victor JD, Conte MM: Local image statistics: maximum-entropy constructions and perceptual salience. J Opt Soc Am A 2012, 29:1313-1345

doi:10.1186/1471-2202-14-S1-P16

Cite this article as: Hermundstad et al:: Natural scene statistics relate to perceptual salience of second-, third-, and fourth-order spatial correlations. BMC Neuroscience 2013 14(Suppl 1):P16.

\section{Submit your next manuscript to BioMed Central} and take full advantage of:

- Convenient online submission

- Thorough peer review

- No space constraints or color figure charges

- Immediate publication on acceptance

- Inclusion in PubMed, CAS, Scopus and Google Scholar

- Research which is freely available for redistribution

Submit your manuscript at www.biomedcentral.com/submit 